\title{
Complications of vision loss and ophthalmoplegia during endoscopic sinus surgery
}

This article was published in the following Dove Press journal:

Clinical Ophthalmology

19 March 2013

Number of times this article has been viewed

\section{Idit Maharshak ${ }^{1,2}$ \\ Jenny K Hoang ${ }^{3}$ \\ M Tariq Bhatti 2,4}

'Department of Ophthalmology, Sackler Faculty of Medicine,

Tel-Avir University, Tel-Aviv, Israel; ${ }^{2}$ Department of Ophthalmology,

${ }^{3}$ Department of Radiology (Division of Neuroradiology), ${ }^{4}$ Department of Medicine (Division of Neurology), Duke Eye Center and Duke University Medical Center, Durham, NC, USA
Correspondence: M Tariq Bhatti Departments of Ophthalmology and Medicine (Division of Neurology), Duke University Eye Center, DUMC 3802, 2351 Erwin Road, Durham, NC 277I0-3802, USA

$\mathrm{Tel}+19196819191$

Fax + I9196840547

Email tariq.bhatti@duke.edu
Objective: To describe two rare cases of concurrent vision loss and external ophthalmoplegia following powered endoscopic sinus surgery (ESS).

Design: Observational case report.

Results: The records of two patients who underwent powered ESS and developed multiple concurrent ophthalmic complications were retrospectively reviewed for clinical history, neuroophthalmologic examination, and imaging findings. Patient 1 developed a retinal vascular occlusion and complete loss of adduction. Patient 2 developed an orbital hemorrhage, optic neuropathy, and a restrictive global ophthalmoplegia. Similar published case reports were also reviewed.

Conclusion: Despite advances in powered ESS technique and instrumentation, serious ophthalmic complications can still occur. Inadvertent entry into the medial orbital wall can result in a combination of blindness and ocular motility dysfunction. The variety of mechanisms responsible for these complications underscores the importance of thorough pre- and postoperative clinical examination and review of imaging studies.

Keywords: sinus surgery, orbit, extra ocular muscle injury, blindness

\section{Introduction}

Sinus surgery is one of the most commonly performed procedures in the United States, with more than 600,000 patients undergoing sinus operations each year. ${ }^{1}$ Since 1985 , when endoscopic sinus surgery (ESS) was first introduced, ${ }^{2}$ it has become the surgical technique of choice for chronic infectious sinusitis, with a growing role in the management of other sinus, orbit, and skull base diseases. ${ }^{3,4}$ The addition of a powered cutting instrument, known as the "hummer," "microdebrider," or "soft-tissue shaver" (Figure 1), has allowed for a less interrupted, more precise, better visualized, and faster sinus surgery. ${ }^{5}$ Despite its advantages, the powered instrument could be harmful due to its ability to rapidly grasp and draw tissue into the blade before cutting, without the surgeon's awareness, which could lead to injury to vital cranial and orbital structures. ${ }^{6-9}$ In a nationwide study on $62,823 \mathrm{ESS}$ cases in the US, the overall major complication rate was $1 \%$, of which orbital injury comprised $0.07 \% .^{10}$

The purpose of this report is to emphasize the ophthalmic hazards associated with powered instrumentation in ESS. We describe two cases in which orbital injuries were sustained during powered ESS, resulting in the rare complication of combined vision loss and ocular motility dysfunction. We conducted a search for cases of this complication that were reported from 1985 to 2012, through the PubMed website, using the keywords "endoscopic sinus surgery," "complications," "orbit," and "vision loss." 


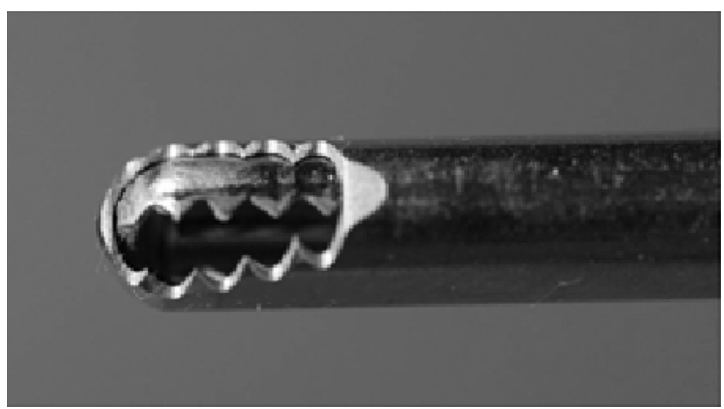

Figure I Distal end of powered cutting instrument (see text for details).

\section{Case I}

A 52-year-old man underwent powered ESS for bilateral ethmoid sinus disease and polyposis. No anatomical anomalies of the medial orbital wall were noted on preoperative computed tomography (CT) imaging. During surgery, the surgeon encountered brisk bleeding in the floor of the left ethmoid sinus. The area of bleeding was controlled with bipolar cautery and eventually packed with gel foam. At the conclusion of the case, the left ethmoid sinus was re-examined and found to be dry with no evidence of active bleeding. In the immediate postoperative period, the patient's left eye was described by his wife as "swollen shut." The patient was discharged without any intervention. The next morning, the eyelid swelling had improved; however, he reported loss of vision in his left eye and the eye was deviated out. An immediate referral was made to an ophthalmologist. A computerized tomography scan of the orbits revealed a bony dehiscence of the medial wall of the orbit and soft tissue changes of the intraorbital injury (Figure 2). Despite 3 days of intravenous methylprednisolone, there was no improvement in vision. Three weeks after the surgery, the patient sought a second opinion at our institution. Visual acuity was 20/20 in the right eye and no light perception (NLP) in the left eye. The pupil of the left eye was amaurotic. Eye movements in the right eye were full. The left eye was unable to adduct and there was a large angle left exotropia in primary gaze (Figure 3A). Forced duction and forced generation testing in the office were negative in the left eye. There was no enophthalmos or proptosis. Dilated fundus examination of the right eye was normal. In the left eye, there was a macular cherry red spot with arterial narrowing (Figure 3B). These findings were in keeping with retinal vascular occlusion. No further intervention was recommended because this condition was considered to be irreversible.

\section{Case 2}

A 65-year-old man underwent powered ESS for recurrent bilateral sinusitis. Intraoperatively, there was bleeding from
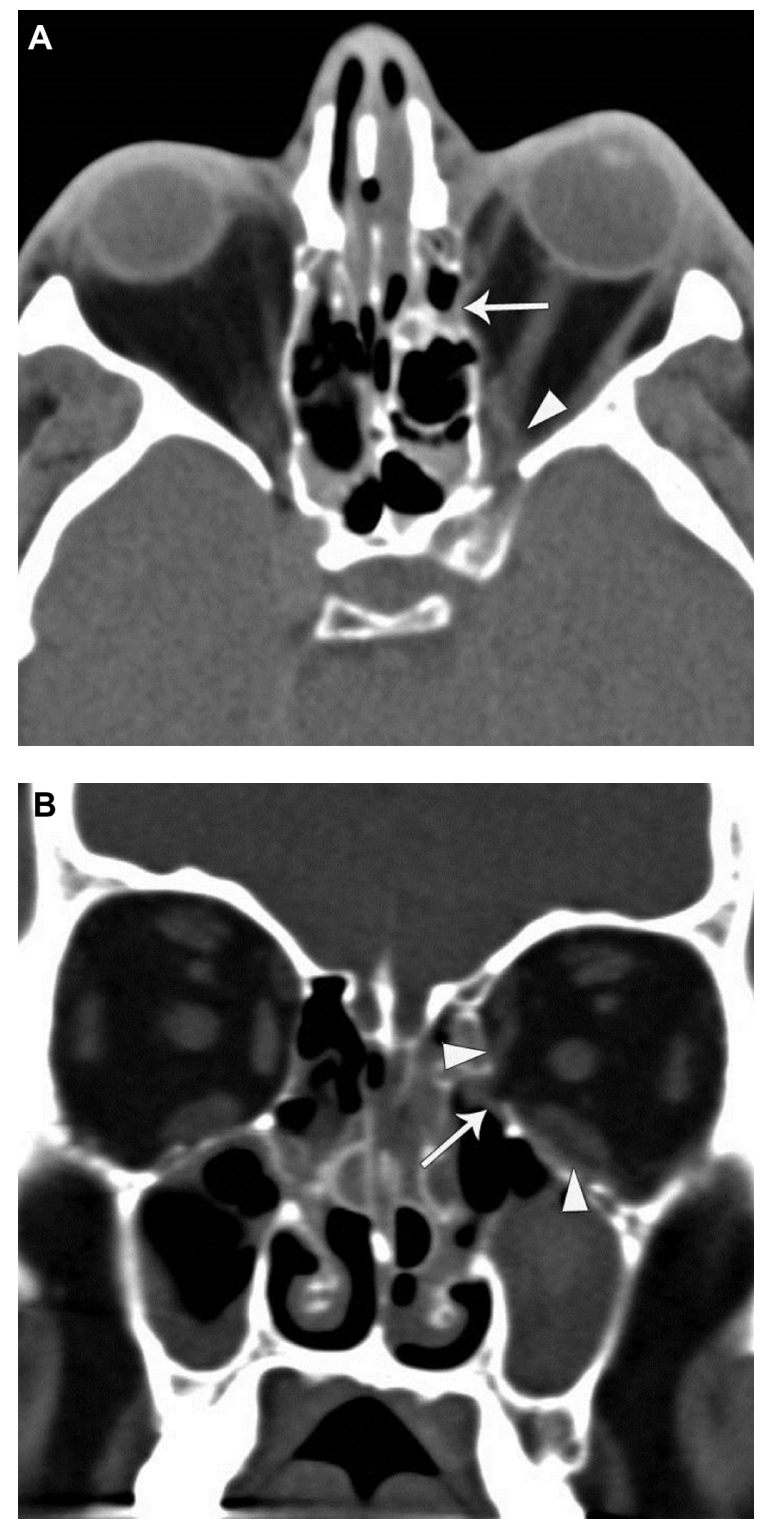

Figure 2 Computed tomography (CT) images of the orbits from Case I. (A) Axial and (B) coronal CT images show bony dehiscence in the medial wall of the left orbit (arrows).

Notes: There is soft tissue thickening at the left orbital apex (arrowhead in A) and loss of normal fat planes around the medial and inferior rectus muscles (arrowheads in B). These findings are consistent with penetration into the left orbit and soft tissue injury (transection of the medial rectus muscle) or inflammation.

the area of the inferomedial right lamina papyracea, and when the surgeon inspected it, he described the inferomedial wall as being dehiscent or inadvertently fractured (he was not clear on the precise interpretation of the finding). The medial and inferior recti muscles were not identified, but adjacent periorbital fat was contacted by the microdebrider. The bleeding from the site required bipolar cauterization and packing. The remainder of the surgery was completed without incident. As the patient was being extubated, there was moderate nasal bleeding from the right nares with the development of right 

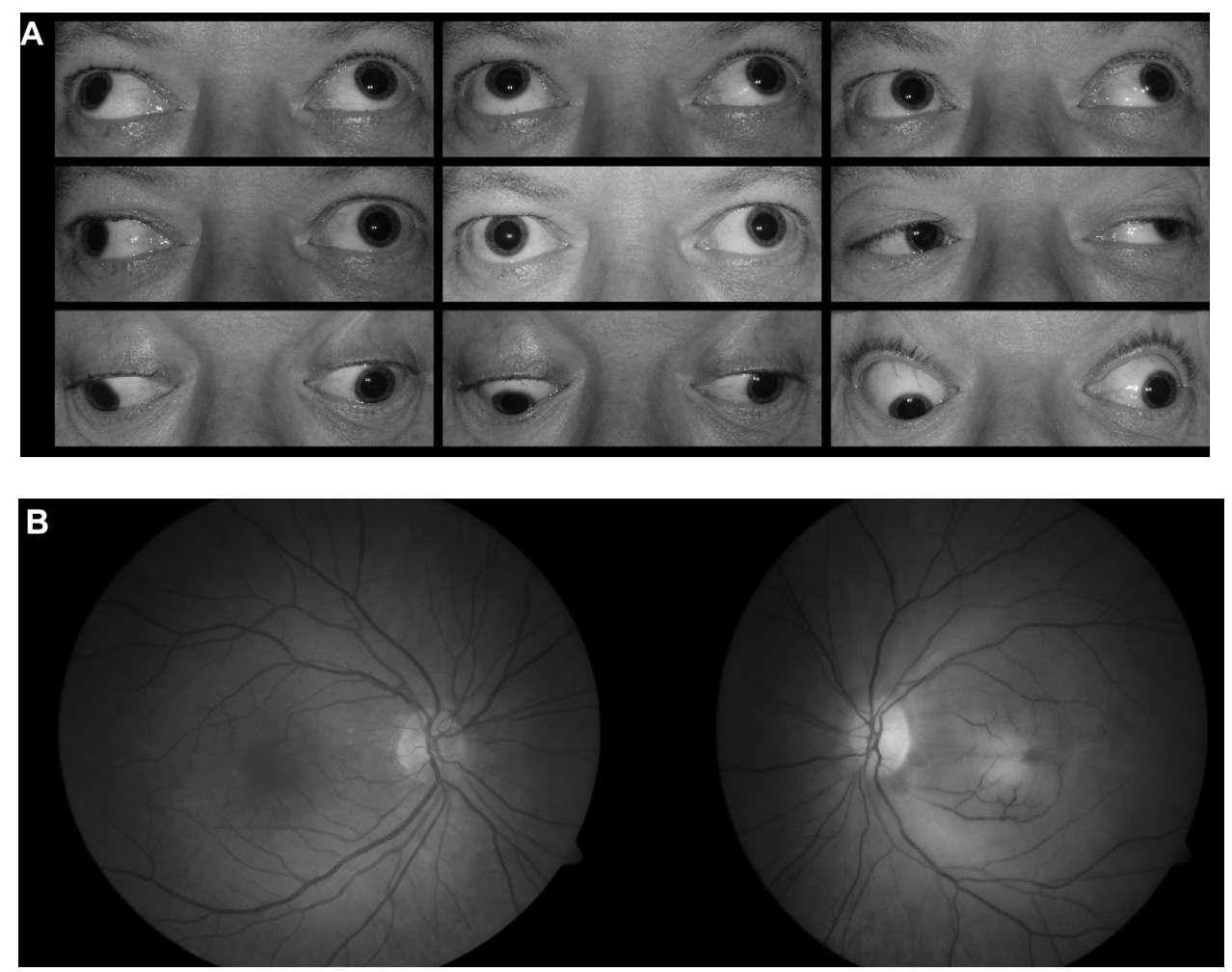

Figure 3 Ocular motility and fundus photographs for Case I. (A) Nine positions of gaze. Eye movements in the right eye were full. There is complete loss of adduction of the left eye. (B) Fundus photographs.

Notes: The right eye was normal. There is a macular cherry red spot with arterial narrowing in the left eye.

orbital edema, ecchymosis, and proptosis. The patient was immediately reintubated. A right lateral canthotomy and cantholysis was performed and intravenous mannitol was administered. An intraoperative ophthalmology consultation was obtained; intraocular pressures were $17 \mathrm{mmHg}$ in the right eye and $21 \mathrm{mmHg}$ in the left eye, and fundus examination was unremarkable. The following morning, the patient reported loss of vision in the right eye. Visual acuity was hand motion in the right eye. There was limited movement of the right eye in all directions, with diffuse periorbital ecchymosis and swelling. A magnetic resonance imaging (MRI) scan of the orbits revealed a hematoma in the inferonasal quadrant of the right orbit (Figure 4A). One month after surgery, the patient was referred to a local neuroophthalmologist. Visual acuity was light perception only in the right eye, with limited movement of the right eye in all gazes, with the addition of $3 \mathrm{~mm}$ of right-eye enophthalmos. He was diagnosed with an orbital apex lesion. A follow-up MRI showed fibrosis in the inferonasal aspect of the orbit (Figure 4B). Two months after surgery, the patient sought a second opinion at our institution. Visual acuity was light perception in the right eye and 20/20 in the left eye. There was a right relative afferent pupillary defect. There was complete ophthalmoplegia of the right eye (Figure 5A). Movement in the left eye was normal. Forced duction testing was positive in the right eye in all directions. There was $2 \mathrm{~mm}$ of right enophthalmos, deepening of superior eyelid sulcus and $2 \mathrm{~mm}$ of lagophthalmos. Dilated fundus examination of the right eye revealed a pale optic nerve with cupping, but was otherwise unremarkable (Figure 5B). No further testing or treatment was recommended.

\section{Discussion}

Two decades ago, grabbing forceps were used by sinus surgeons to strip away mucosa and extirpate soft tissue, followed by the development of suction forceps. ${ }^{11}$ In 1994, a revolutionary powered cutting instrument, termed the "hummer" or "microdebrider," was introduced. ${ }^{5}$ Modified from a preexisting temporomandibular joint instrument, it is constructed of a hollow shaft connected to an aspiration-irrigating device with a rotating or oscillating blade at its distal end. Aspiration of soft tissue and thin bone into the blade allows for precise excision and removal. The rate of aspiration and speed of the blade is controlled by the surgeon. ${ }^{12}$ Despite its advantages, as a powered instrument with strong suction and cutting ability, the microdebrider can rapidly grasp and draw tissue into 
the blade before cutting, without the surgeon's awareness, or pull periorbita and fat into the sinus with removal of orbital tissue without entering the orbit, ${ }^{13}$ which can lead to injury to vital orbital structures. ${ }^{6-9}$ In a study of 62,823 ESS cases, the overall major complication rate was $1 \%$, of which orbital injury comprised $0.07 \% .^{10}$

Vision loss and ophthalmoplegia are two infrequent and devastating complications of ESS. They are rarely seen in combination. In this report, we describe two cases from our clinic and nine more case reports from the literature that had both complications concurrently (Table 1). Each case has distinct clinical and radiographic findings and a distinct mechanism of injury, highlighting the variety of mechanisms that may be involved in the ophthalmic complications associated with powered ESS.

Our first patient exhibited the inability to adduct the left eye. The negative forced duction test indicating a nonrestrictive process and the negative forced generation test indicating loss of muscle activity indicate a diagnosis of loss of function of the medial rectus muscle. Computed tomography showed the muscle had been transected. The medial rectus muscle was the most common extraocular muscle injured in the previously published cases (eight of nine); $;{ }^{8,16-20}$ direct injury or laceration of the medial rectus muscle was present in eight out of the eleven cases. Two cases of ophthalmoplegia were caused by entrapment of the muscle within a defect of the medial orbital wall. ${ }^{16}$ Due to its proximity to the lamina papyracea, the medial rectus muscle is known to be the muscle most susceptible to injury during ESS. ${ }^{12}$ When it is completely transected during powered ESS, surgical correction may not be possible because of the loss of too much muscle mass. ${ }^{21}$ Thus, strabismus surgery was not indicated in Case 1.

In our second patient, there may have been a pre-existing anatomical defect in the medial orbital wall (dehiscent lamina papyracea). In light of the positive forced duction test, we believe the complete ophthalmoplegia was due to inadvertent surgical disruption of the orbital connective tissue framework through the medial orbital wall, resulting in a hematoma that was replaced by fibrosis; ${ }^{7}$ an MRI 1 month after surgery showed that the normal high orbital fat signal was replaced with a low abnormal signal consistent with fibrosis (Figure 4B). Strabismus surgery was not indicated in this case either, as it would have been very difficult to realign the eyes given the underlying mechanism of injury. Also, neither patient was complaining of double vision because of the loss of vision in the same eye.
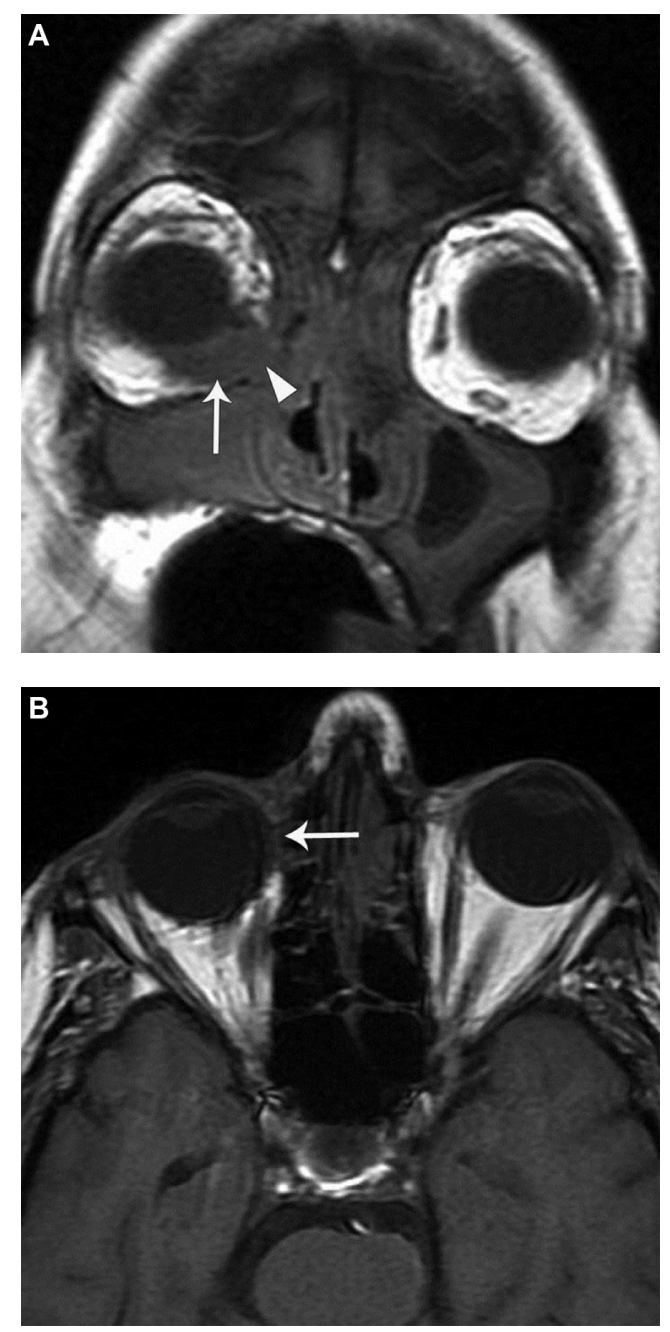

Figure 4 Magnetic resonance (MR) images of the orbits for Case 2. (A) Coronal unenhanced TI-weighted MRI image, approximately 24 hours after surgery, shows a $\mathrm{TI}$ isointense collection in the inferonasal quadrant of the right orbit (arrow), which was most consistent with a hematoma. There is also a bony defect in the medial and inferomedial wall of the orbit (arrowhead) adjacent to the hematoma representing the site of bony penetration. (B) Axial unenhanced TI-weighted MR image from a follow-up MRI, one month after surgery, shows resolution of the hematoma, but there is right enopthalmos and deviation of the globe medially.

Notes: The abnormal position of the globe associated with an abnormal signal in the inferonasal aspect of the orbit (arrow, and seen on other images from MRI) is consistent with fibrotic tissue causing globe/muscle tethering.

Ocular motility complications of ESS may result from direct damage to the muscle from contusion, destruction, or transection; ;,8,17-20,22 entrapment of the muscle within a bony orbital wall defect; ${ }^{16,23}$ oculomotor nerve injury; ${ }^{24}$ or disruption of the orbital connective tissue system. ${ }^{7}$

All eleven cases in Table 1 had concomitant vision loss with different degrees of severity. Three cases had retinal vascular occlusion, ${ }^{17,19}$ and the most serious of all cases had bilateral vision loss and ophthalmoplegia. ${ }^{17}$ Vision loss is a less common complication than ophthalmoplegia. In our first patient, the visual loss was probably due to ophthalmic artery occlusion or a combined central retinal artery occlusion and 

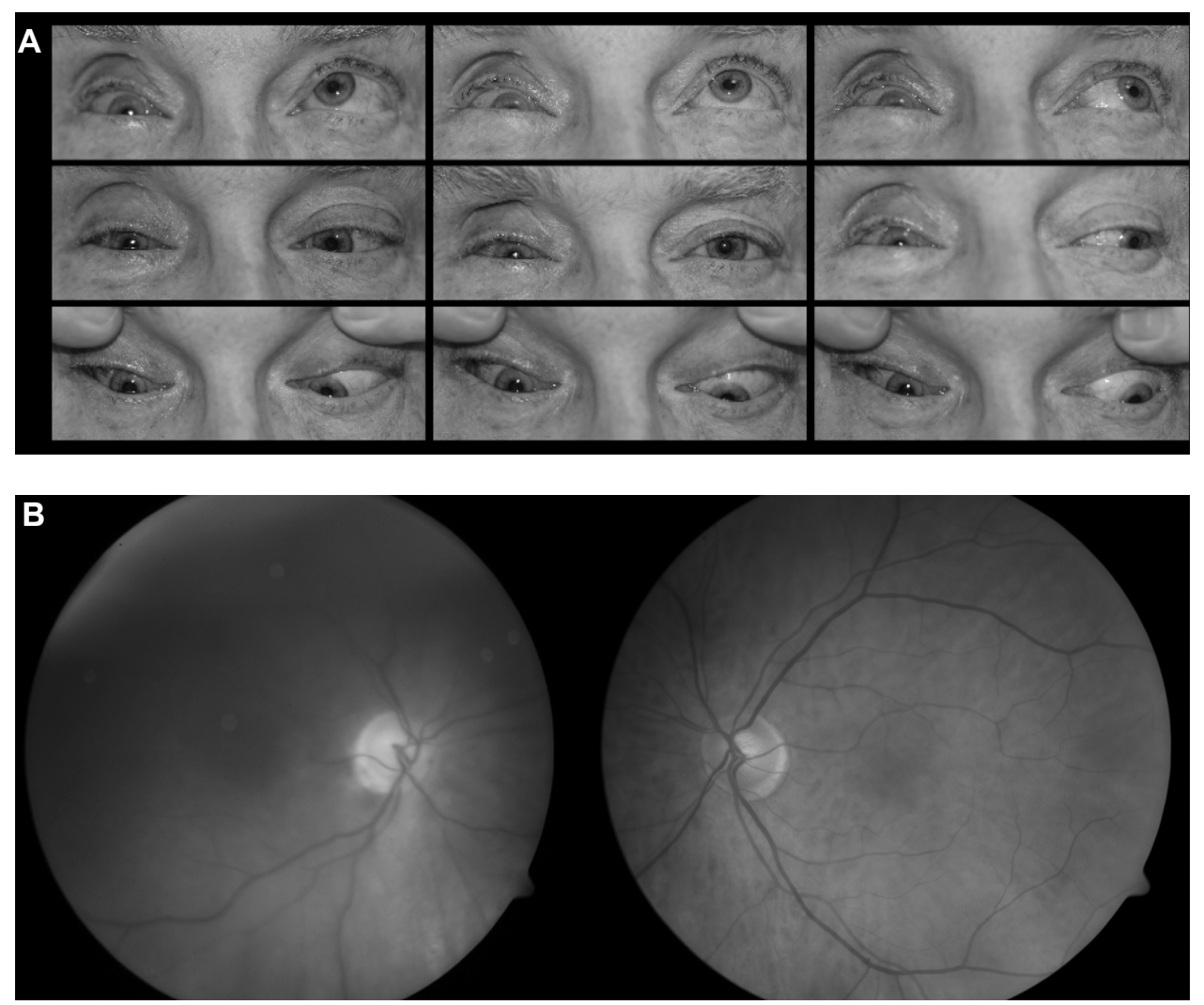

Figure 5 Ocular motility and fundus photographs for Case 2. (A) Nine positions of gaze. The right eye does not move in any direction. (B) Fundus photographs. Note: The right optic nerve pallor with cupping.

optic nerve injury, as NLP vision rarely, if ever, results from central retinal artery occlusion alone. This case joins the few published reports of retinal vascular occlusion as a cause of vision loss following ESS. ${ }^{17,19,25,26}$ In our second patient, fundoscopic examination showed a pale optic nerve, a non-specific finding that does not help define the underlying mechanism of injury. We believe the vision loss was a result of either the orbital hematoma causing a compressive optic neuropathy or the use of cautery resulting in direct injury to the optic nerve. Orbital hemorrhage is known to be the most reported ophthalmic complication associated with $\mathrm{ESS}^{12}$ and can, as in our patient, result in indirect (compressive) optic nerve injury. ${ }^{8,16,18} \mathrm{~A}$ meta-analysis of 2583 patients undergoing ESS found a $0.12 \%$ incidence of orbital complications, the vast majority being orbital hemorrhage, ${ }^{27}$ caused by unintentional entry into the orbit through the lamina papyracea. ${ }^{28}$

The other possible mechanism of optic nerve injury in our patient is direct trauma from the use of cautery. There are few reports of irreversible unilateral and bilateral visual loss caused by direct injury to the optic nerve from the electrocoagulator and microdebrider. ${ }^{17,19,20,29,30}$ There is no proven treatment for direct traumatic optic neuropathy.
Several procedures and measures have been recommended by ENT surgeons in order to avoid orbital hematoma/ blindness when performing powered ESS. ${ }^{13}$ High risk patients should be recognized through review of CT scans for preoperative orbital dehiscence, expansion by disease, and thinning. The location of the medial rectus against the lamina papyracea should be noted, as well as whether the anterior ethmoid artery is below the skull base in the ethmoid sinus and subject to trauma and retraction into the orbit, and whether the maxillary sinus is hypoplastic. ${ }^{13}$ In surgery, the key to preventing orbital injury is identifying the lamina papyracea. Surgery without endoscopic guidance and visualization increases the risk of orbital complication. The most helpful way to identify any opening in the lamina papyracea is to use simultaneous endoscopic exam and eye palpation, the so-called bulb press test, which was first identified in a 1989 report by Stankiewicz et al. ${ }^{13,14}$

During surgery, any patient who has orbital fat exposure should be observed for orbital hematoma. Visible orbital fat indicates a probable orbital hematoma. Time is critical when dealing with increased intraorbital pressure - more so with an acute arterial or fast hematoma. Pressure can build quickly 


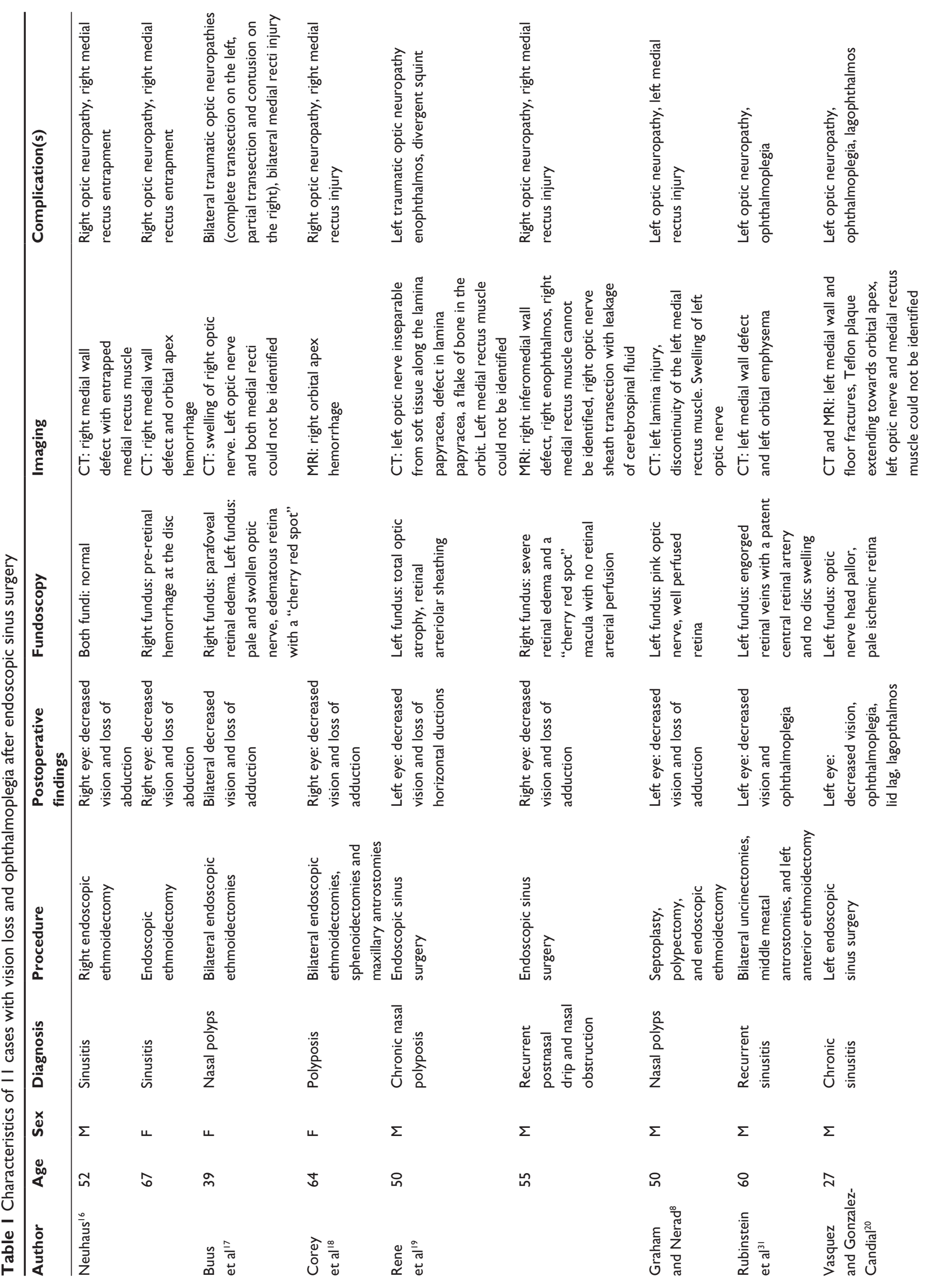



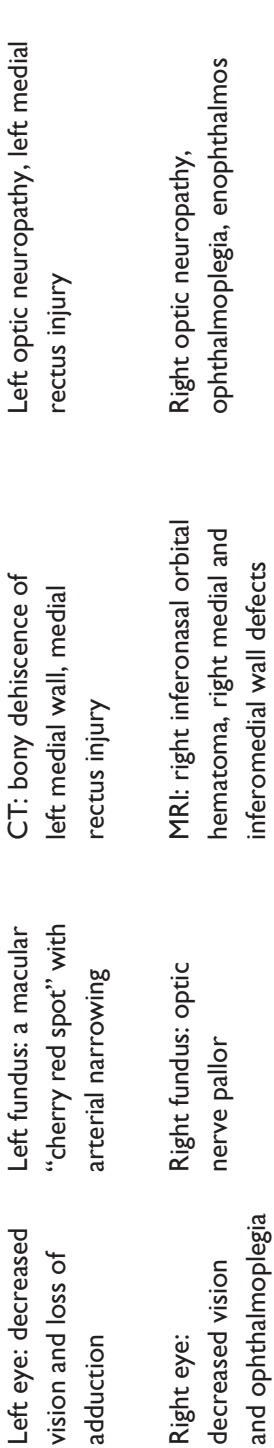

in a confined space such as the orbit. Reversal of critical pressure is the key to success. ${ }^{14,15}$ Orbital massage should be instituted and pressure measured with an ophthalmometer, if available. If the eye is persistently hard and tense or pressure continues to be elevated, a lateral canthotomy with cantholysis should be performed only if the surgeon knows how to perform the procedure. Unfortunately, cantholysis and canthotomy are not taught in most training programs because they are looked upon as ophthalmology procedures. Perhaps, in high risk patients, the surgeon performing the operation should be experienced with this procedure. ${ }^{13}$

Unfortunately, there is very little room for treatment in cases of direct optic nerve injury ${ }^{13}$ and treatment is difficult when significant muscle mass loss has occurred as a result of transection. ${ }^{21}$

A comprehensive review of the preventive measures and treatment that can be applied by the sinus surgeon during or after powered ESS is beyond the scope of this paper.

\section{Conclusion}

Sinus surgery can cause major complications in the orbit, which is a different anatomical system. Surprisingly, in the last 18 years, only nine cases of combined vision loss and ophthalmoplegia have been reported. Two of these cases were examined at the Duke Eye Center during the last year. We therefore conclude that the scarcity of published cases may be due to underreporting or underdiagnosis, perhaps due to insufficient awareness and collaboration between sinus surgeons and ophthalmologists. We believe it is important that both should be familiar with the mechanisms leading to these concurrent complications of ESS and should enhance collaboration for facilitating better recognition, treatment, and reporting of these cases.

\section{Acknowledgment}

This report was supported by a 2011-2012 Duke University unrestricted departmental grant from Research to Prevent Blindness. All authors contributed to the final approval of the version to be published.

\section{Disclosure}

The authors report no conflicts of interest in this work.

\section{References}

1. Psaltis AJ, Soler ZM, Nguyen SA, Schlosser RJ. Changing trends in sinus and septal surgery, 2007 to 2009. Int Forum Allergy Rhinol. 2012;2(5): 357-361.

2. Vining EM, Kennedy DW. The transmigration of endoscopic sinus surgery from Europe to the United States. Ear Nose Throat J. 1994;73(7): 456-458, 460. 
3. Cohen NA, Kennedy DW. Endoscopic sinus surgery: where we are - and where we're going. Curr Opin Otolaryngol Head Neck Surg. 2005;13(1): $32-38$.

4. Lund VJ. Extended applications of endoscopic sinus surgery - the territorial imperative. J Laryngol Otol. 1997;111(4):313-315.

5. Setliff RC 3rd. The hummer: a remedy for apprehension in functional endoscopic sinus surgery. Otolaryngolc Clin North Am. 1996;29(1): 95-104.

6. Berenholz L, Kessler A, Sarfaty S, Segal S. Subarachnoid hemorrhage: a complication of endoscopic sinus surgery using powered instrumentation. Otolaryngol Head Neck Surg. 1999;121(5):665-667.

7. Bhatti MT, Giannoni CM, Raynor E, Monshizadeh R, Levine LM. Ocular motility complications after endoscopic sinus surgery with powered cutting instruments. Otolaryngol Head Neck Surg. 2001;125(5): 501-509.

8. Graham SM, Nerad JA. Orbital complications in endoscopic sinus surgery using powered instrumentation. Laryngoscope. 2003;113(5): 874-878.

9. Hackman TG, Ferguson BJ. Powered instrumentation and tissue effects in the nose and paranasal sinuses. Curr Opin Otolaryngol Head Neck Surg. 2005;13(1):22-26.

10. Ramakrishnan VR, Kingdom TT, Nayak JV, Hwang PH, Orlandi RR. Nationwide incidence of major complications in endoscopic sinus surgery. Int Forum Allergy Rhinol. 2012;2(1):34-39.

11. Kennedy DW, Senior BA. Endoscopic sinus surgery. A review. Otolaryngol Clin North Am. 1997;30(3):313-330.

12. Bhatti MT, Stankiewicz JA. Ophthalmic complications of endoscopic sinus surgery. Surv Ophthalmol. 2003;48(4):389-402.

13. Stankiewicz JA, Lal D, Connor M, Welch K. Complications in endoscopic sinus surgery for chronic rhinosinusitis: a 25-year experience. Laryngoscope. 2011;121(12):2684-2701.

14. Stankiewicz JA. Blindness and intranasal endoscopic ethmoidectomy: prevention and management. Otolaryngol Head Neck Surg. 1989;101(3):320-329.

15. Stankiewicz JA, Chow JM. Two faces of orbital hematoma in intranasal (endoscopic) sinus surgery. Otolaryngol Head Neck Surg. 1999;120(6):841-847.

16. Neuhaus RW. Orbital complications secondary to endoscopic sinus surgery. Ophthalmology. 1990;97(11):1512-1518.

17. Buus DR, Tse DT, Farris BK. Ophthalmic complications of sinus surgery. Ophthalmology. 1990;97(5):612-619.
18. Corey JP, Bumsted R, Panje W, Namon A. Orbital complications in functional endoscopic sinus surgery. Otolaryngol Head Neck Surg. 1993;109(5):814-820.

19. Rene C, Rose GE, Lenthall R, Moseley I. Major orbital complications of endoscopic sinus surgery. Br J Ophthalmol. 2001;85(5):598-603.

20. Vasquez LM, Gonzalez-Candial M. Permanent blindness after endoscopic sinus surgery. Orbit. 2011;30(2):108-110.

21. Trotter WL, Kaw P, Meyer DR, Simon JW. Treatment of subtotal medial rectus myectomy complicating functional endoscopic sinus surgery. JAAPOS. 2000;4(4):250-253.

22. Thacker NM, Velez FG, Demer JL, Wang MB, Rosenbaum AL. Extraocular muscle damage associated with endoscopic sinus surgery: an ophthalmology perspective. Am J Rhinol. 2005;19(4):400-405.

23. Carton A, Hislop S. Orbital floor injury with extraocular muscle entrapment following functional endoscopic sinus surgery. Br Journal Oral Maxillofac Surg. 2000;38(1):82-83.

24. Bayramlar H, Miman MC, Demirel S. Inferior oblique paresis, mydriasis, and accommodative palsy as temporary complications of sinus surgery. J Neuroophthalmol. 2004;24(3):225-227.

25. Shi JB, Chen FH, Xu R, et al. [Ophthalmic complication and management of endoscopic sinus surgery.] Zhonghua Er Bi Yan Hou Tou Jing Wai Ke Za Zhi. 2008;43(2):114-119. Chinese.

26. Liu TT, Han M, Zhang NK. [Embolism of central retinal artery following endoscopic sinus surgery leads to blindness: a case report.] Zhonghua Er Bi Yan Hou Tou Jing Wai Ke Za Zhi. 2010;45(3):253. Chinese.

27. May M, Levine HL, Mester SJ, Schaitkin B. Complications of endoscopic sinus surgery: analysis of 2108 patients - incidence and prevention. Laryngoscope. 1994;104(9):1080-1083.

28. Bhatti MT, Schmalfuss IM, Mancuso AA. Orbital complications of functional endoscopic sinus surgery: MR and CT findings. Clin Radiol. 2005;60(8):894-904.

29. Vanden Abeele D, Clemens A, Tassignon MJ, van de Heyning PH. Blindness due to electrocoagulation following functional endoscopic sinus surgery. J Laryngol Otol. 1996;110(3):261-264.

30. Kim JY, Kim HJ, Kim CH, Lee JG, Yoon JH. Optic nerve injury secondary to endoscopic sinus surgery: an analysis of three cases. Yonsei Med J. 2005;46(2):300-304.

31. Rubinstein A, Riddell CE, Akram I, Ahmado A, Benjamin L. Orbital emphysema leading to blindness following routine functional endoscopic sinus surgery. Arch Ophthalmol. 2005;123(10):1452.
Clinical Ophthalmology

\section{Publish your work in this journal}

Clinical Ophthalmology is an international, peer-reviewed journal covering all subspecialties within ophthalmology. Key topics include: Optometry; Visual science; Pharmacology and drug therapy in eye diseases; Basic Sciences; Primary and Secondary eye care; Patient Safety and Quality of Care Improvements. This journal is indexed on Submit your manuscript here: http://www.dovepress.com/clinical-ophthalmology-journal

\section{Dovepress}

PubMed Central and CAS, and is the official journal of The Society of Clinical Ophthalmology (SCO). The manuscript management system is completely online and includes a very quick and fair peer-review system, which is all easy to use. Visit http://www.dovepress.com/ testimonials.php to read real quotes from published authors. 